\title{
INDIVIDUALISMO: O PAPEL DA “COMUNIDADE FANTASMA” COMO REDE SOCIAL INCORPORADA NA CONSTRUÇÃO DO COMPORTAMENTO INDIVIDUAL DESVIANTE
}

\author{
INDIVIDUALISM: THE ROLE OF THE "PHANTOM COMMUNITY" AS \\ AN INCORPORATED SOCIAL NETWORK IN THE CONSTRUCTION OF \\ DEVIANT INDIVIDUAL BEHAVIOR
}

\author{
Vítor Teixeira $^{1}$
}

\section{RESUMO}

A emergência do individualismo é apresentada como um ciclo vicioso de socialização-internalização-socialização. $\mathrm{O}$ individualismo emerge baseado no grau de respostas comportamentais permitidas no processo de socialização e do "outro generalizado" incorporado durante esse processo. Comportamento desviante surge aqui como uma característica individual das comunidades minor, cada uma com suas específicas práticas de socialização e (sub)cultura, cujas atitudes e expectativas colectivas e "comunidade fantasma" são incongruentes com o comportamento esperado pela comunidade de maior escala ou sociedade. A manipulação da rede social de um indivíduo providencia a oportunidade de induzir "outros fantasma" socialmente saudáveis e prevenir comportamentos desviantes.

Palavras-chave: Socialização. Interaccionismo simbólico. Redes sociais. Individualismo. Comportamento desviante.

\begin{abstract}
The emergence of individualism and deviant behavior is presented as a vicious cycle of socialization-internalization-socialization. Individualism emerges based on the degree of behavioral responses allowed in the socialization process and from the "generalized other", as such incorporated. With different types of minor communities, all with particular socialization practices and (sub)cultures, deviant behavior emerges here as an individual characteristic of minor communities whose collective attitudes, expectations and "phantom community" are incongruent with the expected behavior of the larger community. The manipulation of a subject's social network provides the opportunity to induce socially healthy "phantom others" and prevent deviant behavior.
\end{abstract}

Keywords: Socialization. Symbolic interactionism. Individualism. Deviant behavior.

1 Centro de Estudos Sociais, Faculdade de Economia, Universidade de Coimbra, Portugal. E-mail: vitor.e.teixeira@gmail.com. 


\section{Introdução}

O presente trabalho procura demonstrar a emergência do comportamento individual desviante como resultado da internalização do conjunto de comportamentos e expectativas de membros da zona íntima de uma rede social, internalização cujo produto foi teorizado e apelidado de "comunidade fantasma" por Lonnie Athens (1992, 1994, 1995, 1997, 1998, 2005; RHODES, 1999). O comportamento desviante delimita a diferença entre conformismo e individualismo.

O seguinte texto encontra-se dividido em três segmentos: 1) socialização, "outro generalizado" e conformismo, em que se evidenciará como a socialização estreita (ARNETT, 1995) conduz ao conformismo das normas e valores de uma sociedade pelos seus membros através do "outro generalizado" (ARNETT, 1995; ATHENS, 1997; MEAD, 1925; RHODES, 1999); 2) "comunidade fantasma", individualismo e comportamento desviante, em que se esclarecerá de que forma a "comunidade fantasma" é a causa do individualismo e do comportamento desviante (no âmbito deste trabalho, entende-se como comportamento desviante aquele tipo de comportamento que não corresponde às expectativas das normas de conduta e valores de uma determinada cultura ou especificamente do contexto cultural em que ocorre o ato) (ATHENS, 1992, 1997, 1998; RHODES, 1999); e 3) comunidade e rede social, em que se procurará apresentar a análise de redes sociais como instrumento de manipulação da "comunidade fantasma" em momentos de transformação dramática (ATHENS, 1995, 1997; RHODES, 1999).

O sistema a esboçar nas seguintes páginas é que o comportamento individual nasce do tipo de socialização a que o sujeito é submetido e da "comunidade fantasma" que incorpora por consequência do tipo de socialização e dos indivíduos que tiveram impacto social significativo. Este sujeito fará parte de uma subcomunidade que, no entanto, em momentos de transformação dramática que modificará a sua "comunidade fantasma", poderá ser ela própria (a subcomunidade que habita) modificada pelo sujeito ou o sujeito poderá mudar-se para uma outra subcomunidade (corpórea) que se adeque à sua nova "comunidade fantasma". Este sujeito fará agora parte da rede social e da socialização de outros indivíduos da nova subcomunidade onde se instalou, podendo ser ele próprio incorporado como membro na "comunidade fantasma" de outros indivíduos, formando assim um ciclo vicioso de socialização-incorporação-socialização.

\section{Socialização, "outro generalizado" e conformismo}

Desde que nascemos, fazemos parte de uma comunidade e/ou sociedade, da qual aprendemos suas normas e valores através de membros dessa sociedade e membros da rede social. A esta aprendizagem denominamos de socialização, o processo pelo qual um sujeito é sistematicamente bombardeado sensorial e emocionalmente com manifestações das referidas normas e valores.

Em um artigo de 1995, Arnett apresentou duas formas distintas de socialização: socialização alargada e socialização estreita. Parafraseando o autor, socialização alargada refere-se às culturas que promovem individualismo, independência e autoexpressão, enquanto, em comparação, culturas cujos valores máximos a atingir são obediência e conformidade são caracterizadas com um processo de socialização estreita. $\mathrm{O}$ autor nota, no final do artigo, que a distinção entre culturas com socialização alargada e culturas com socialização estreita não deve ser tomada como a distinção entre sociedades "simples" e "complexas". Os exemplos utilizados são os EUA, com uma socialização alargada, e o Japão com uma socialização estreita. Ambas são sociedades categorizadas como "complexas" que, no entanto, mantém opostos modos de socialização. O autor nota ainda que ambos os tipos de socialização não são mutuamente exclusivos e que existem processos de socialização com diferentes gradações entre socialização alargada e socialização estreita.

Segundo Arnett (1995), o ponto fulcral no processo de socialização é o tipo de limites que culturas impõem no desenvolvimento de indivíduos e o grau de variação que admitem no seu comportamento (este grau de variação é também identificado como características individuais que definem cada sujeito). A principal distinção entre socialização estreita 
e alargada é precisamente os limites que ambas impõem aos indivíduos e a variação de comportamentos que permitem. Como se pode deduzir, os limites impostos por uma socialização estreita são bastante mais reduzidos do que os limites impostos por uma socialização alargada. Por sua vez, a variação de características individuais é igualmente menor em culturas caracterizadas por uma socialização estreita, e maior em culturas caracterizadas por uma socialização alargada.

Arnett (1995) descreve várias fontes de socialização, porém, a fonte mais importante a ter em conta em qualquer tipo de processo de socialização é o sistema de crenças culturais. As fontes restantes (família, pares, escola e trabalho, comunidade, mídia e sistema legal) dependem em certa medida do sistema de crenças culturais, providenciando a base ideológica para essas outras fontes de socialização. Este sistema de crenças culturais não é nada mais do que o sistema de normas e padrão moral de uma sociedade, o que, por sua vez, determina o que é esperado do comportamento de cada sujeito. A transmissão do sistema de normas e padrão moral, incluindo os limites e características individuais acima mencionadas, pode ser feita de forma direta, como uma ordem formal, ou indireta, como através de peer pressure.

Uma forma indireta e sutil de transmitir os limites e características individuais de cada cultura e inerente forma de socialização é através da sensibilização do sujeito ao que é esperado do comportamento dele pelos outros membros da comunidade, ou seja, das expectativas que os outros membros têm do sujeito. Ou, tal como Mead (1925, p.47) refere:

Social control depends, then, upon the degree to which the individuals in society are able to assume the attitudes of the others who are involved with them in common endeavor

A força destas expectativas depende em larga medida de como estas são experimentadas através das interações sociais. É esta percepção das expectativas dos outros que constitui o que Mead conceitualizou como o "outro generalizado" (ARNETT, 1995; ATHENS, 1992, 1994; RHODES, 1999), em que cada sujeito incorpora a atitude coletiva da sua comunidade, ergo, as expectativas dos indivíduos com quem interage e que pertencem à sua rede social alargada, e de onde cada sujeito retira a sua personalidade (RHODES,
1999). É também através desta incorporação que cada sujeito atribui significado às interações sociais.

Athens (1994, p. 522) ilustra melhor a lógica inerente da incorporação do "outro generalizado":

When people take the attitude of a single individual, they tell themselves what a particular individual expects of them; when they take the attitude of a single group, they tell themselves what a particular group expects of them; but when they take the attitude of the generalized other, they tell themselves what everyone in their community expects of them.

Note-se que este "outro generalizado" explica porque indivíduos se conformam e seguem as normas, isto é, as expectativas da comunidade, mas falha em explicar individualismo e comportamento desviante. Explica porque os sujeitos concordam uns com os outros, mas não explica porque eles discordam (ATHENS, 1994, 2007; RHODES, 1999). Por esta razão, Athens propôs a existência de uma entidade mais íntima que o "outro generalizado", que atribui a cada sujeito suas características individuais e que permite que dois sujeitos da mesma comunidade e na mesma situação ajam de forma diferente: a "comunidade fantasma” (ATHENS, 1992, 1994; RHODES, 1999).

\section{"Comunidade fantasma", individualismo e comportamento desviante}

Ao longo deste trabalho que se tem referido à "comunidade fantasma" somente como a incorporação da rede social íntima de um sujeito e que é a base do comportamento individual. Mas o que realmente significa "comunidade fantasma"?

"Comunidade fantasma" é, especificamente, a internalização de determinados membros da zona íntima da rede social do sujeito-âncora, seguindo a terminologia usada por Mitchell (1974), bem como a internalização das suas atitudes e expectativas (ATHENS, 1994; RHODES, 1999). A "comunidade fantasma" surge como a oposição individualista ao conformismo do "outro generalizado".

Athens (1994) segue o trabalho de George Herbert Mead acerca da construção do ego. Para estes autores, o ego é o resultado de solilóquios entre 
duas entidades: o "eu", que representa o impulso ou vontade de atuar, e o "me", que é o conjunto organizado de atitudes de outros indivíduos que o ego (sujeito) assume como suas. É o "me" que controla conscientemente as ações do sujeito para que elas correspondam às expectativas de outros indivíduos da comunidade do sujeito. Este "me" é precisamente o "outro generalizado" (vide citação prévia de ATHENS, 1994).

No entanto, tal como referido acima, este modelo explica somente porque vários sujeitos concordam, mas não porque discordam entre si. A partir deste problema, Athens assumiu que cada sujeito deve trazer algo único consigo para cada consigo, algo que explicasse porque dois sujeitos tiveram interpretações diferentes de uma mesma situação (ATHENS, 1994; RHODES, 1999). Caso contrário não haveria individualidade alguma se todos os sujeitos assumissem as atitudes do "outro generalizado" de uma mesma comunidade.

Athens (ibid.) propõe, então, outra entidade mais específica a cada indivíduo que justificasse o seu individualismo. Uma entidade semipermanente composta por outros indivíduos significantes (membros do seu grupo primário - zona íntima da rede social) para o sujeito, que o acompanha e "dialoga" com o seu "eu" a todo o momento. Sem esta entidade semipermanente o sujeito seria obrigado a reinventar-se cada vez que surgia uma nova situação. As atitudes incorporadas dos indivíduos significantes ao sujeito podem ser visualizadas como "outros fantasma", e o seu conjunto forma a "comunidade fantasma". Mas o que torna esta "comunidade fantasma" tão individualista e única a cada sujeito?

Como está sempre presente, a "comunidade fantasma" entra no solilóquio do sujeito, substituindo o "outro generalizado" e respondendo diretamente às questões do ego. As emoções e interpretações que o sujeito sente e tem são os significados atribuídos pela "comunidade fantasma" às sensações corporais (ATHENS, 1994; RHODES, 1999). O sujeito é e faz, então, o que a "comunidade fantasma" lhe diz.

Os membros da "comunidade fantasma" são indivíduos da zona primária da rede social do sujeito cujas atitudes e expectativas são incorporadas e internalizadas pelo sujeito no decorrer de experiências sociais, ou, em outras palavras, no decorrer da socialização do sujeito. Essas experiências sociais são, no entanto, significativas para o sujeito, contrapondo-se em qualidade e quantidade às experiências sociais triviais (ATHENS, 1992, 1994). Experiências sociais significativas têm impacto na vida do sujeito que pode durar semanas, meses ou até anos após o seu decorrer (ATHENS, 1992, 1994, 1995; RHODES, 1999). Uma característica importante referida por Arnett (1995) é a afeição (attachment, no original) que o sujeito pode ter por outros indivíduos da sua comunidade. Afeto, para uns, é uma forte força de motivação para o sujeito para cumprir as expectativas de aqueles por quem tem afeto. Afeto, para outros, impõe ao sujeito a vontade de agradar, de seguir as suas expectativas tanto ideologicamente como a nível do comportamento (ARNETT, 1995). A teoria dos laços sociais de Travis Hirschi (ADLER et al., 2007; BARNES, 2007; PAYNE; SALOTTI, 2007) postula que é o afeto pela família, professores e pares que impedem o sujeito de ter comportamentos desviantes.

No entanto, o sujeito não age com individualista somente por ter uma "comunidade fantasma". $\mathrm{O}$ individualismo do sujeito advém quando as expectativas da sua "comunidade fantasma' não correspondem às expectativas do "outro generalizado" e o sujeito atua de acordo com o comportamento apontado pela comunidade fantasma como o mais indicado para a situação em que se encontra. Mas, apesar de em desacordo com a expectativa do "outro generalizado", o plano de ação do sujeito, embora individualista, não quebra as normas ou os valores da sua comunidade. Assumo a este ponto que a cultura do sujeito aplica uma socialização alargada em que é permitida uma maior variação no comportamento individual sem "quebrar as regras". Em culturas com socialização estreita, a reduzida variação no comportamento individual corresponde, teoricamente, a uma "comunidade fantasma" em permanente concordância com o "outro generalizado". Como surge, então, o comportamento desviante?

\section{Comunidade, dominância e rede social}

Tal como referido no início do texto, no âmbito deste trabalho considera-se como comportamento 
desviante aquele tipo de comportamento que não corresponde às expectativas das normas de conduta ou valores de uma determinada cultura, ou especificamente do contexto cultural em que ocorre o ato.

Segundo Athens (1997, 1998; RHODES, 1999), existem vários tipos de comunidades minors dentro de maiores comunidades corpóreas. Subcomunidades, digamos, cujas diferenças se baseiam no tipo de indivíduos que habitam essa subcomunidade, a norma estabelecida para resolver disputas de dominância dentro da subcomunidade e a gravidade do crime violento nessa subcomunidade. Apesar de esta distinção ter sido desenvolvida com base no grau de violência, não deixa de demonstrar que diferentes tipos de subcomunidades praticam diferentes formas de socialização com base nas normas estabelecidas, podendo ainda inferir-se que cada subcomunidade acarreta também uma subcultura adjacente.

Athens (1998; RHODES, 1999) delineou três tipos de subcomunidades: civis; turbulentas; e malignas.

Em subcomunidades civis, o tipo de indivíduos prevalentes têm "comunidades fantasma" anti-violentas que se encontram em concordância com a expectativa da subcomunidade corpórea e em concordância também, em parte, com a expectativa da comunidade maior. Consequentemente, membros desta subcomunidade utilizavam meios não violentos para resolver disputas de dominância (ibid.).

Em subcomunidades turbulentas não existe nenhum tipo de indivíduo prevalente, nem normas estabelecidas de como resolver disputas de dominância. Portanto, enquanto alguns membros desta subcomunidade recorrem à violência para estabelecer dominância sobre os restantes membros, outros indivíduos não recorrerão à violência para resolver disputas de dominância (ibid.).

Em subcomunidades malignas, o tipo de indivíduos prevalentes têm "comunidades fantasma" não mitigadas que aconselham o indivíduo a agir com extrema violência em situações de confronto, o que é congruente com a expectativa da subcomunidade corpórea, mas em dissonância com a expectativa da comunidade maior. As disputas de dominância são frequentemente resolvidas com recurso à violência (ibid.).

Todos os atos violentos que ocorram nestas subcomunidades são comportamentos desviantes quando comparados com o que é esperado pela comunidade maior, mas para as subcomunidades (exceto a civil), esses atos violentos são comportamentos aceitáveis e congruentes com as normas estabelecidas. Ou seja, para o "outro generalizado" da comunidade maior, o comportamento individual violento de membros das subcomunidades maligna e turbulenta é o comportamento desviante.

Mas as subcomunidades não se mantêm iguais ao longo dos tempos, nem se mantêm iguais os tipos de indivíduos que as compõem. Como na base do comportamento individual se encontra a "comunidade fantasma", só com a modificação da "comunidade fantasma" se modifica o tipo de indivíduo (ATHENS, 1998).

Porém, a "comunidade fantasma" cresce por um meio social e cultural específico e está adaptada a esse meio. Contudo, Athens (1995; RHODES, 1999) argumenta que, através de experiências traumáticas excruciantes, a "comunidade fantasma" pode ser desfeita e recriada, processo que apelida de transformação dramática. Este processo tem cinco fases principais: fragmentação; unidade provisória; práxis; consolidação; e segregação social. Tome-se como exemplo teórico o caso de um sujeito de uma subcomunidade civil que, por razões diversas, se muda para uma subcomunidade maligna.

Este sujeito é submetido a experiências sociais traumáticas na nova subcomunidade, o tipo de experiências para as quais a "comunidade fantasma" que transporta da sua anterior subcomunidade civil não tem capacidade de lidar ou responder com sucesso. Ele fica sem saber como agir, pois os "outros fantasma" que o acompanham também não sabem como agir. Esta experiência social é tão traumática e estranha ao ego que este acaba por se fragmentar. É uma experiência estranha, pois não se enquadra em nenhuma das presunções que o sujeito tinha do mundo. A vontade de agir é tremenda, mas sem saber como fazê-lo, a "comunidade fantasma" fragmenta-se. Como a "comunidade fantasma" é parte integrante do ego, com esta experiência social o sujeito perde também parte de si. O sujeito sente-se:

$[\mathrm{H}]$ elpless and vulnerable in a world that seems to have suddenly turned upside down and become alien (ATHENS, 1995, p. 574).A segunda fase, unidade provisória, começa com o sujeito a questionar-se acerca da experiência social traumática que sofreu e a questionar-se acerca das presunções que tinha anteriormente e descobre que estas estavam erradas e são inadequadas para compreender sua nova realidade. Enquanto resolve as questões que surgiram, o sujeito continua a ter experiências 
sociais e, sem a "comunidade fantasma", continua sem saber como agir. O sujeito procura, então, ativamente por conselho de outros indivíduos experientes, mas à falta destes, o sujeito aceita quaisquer conselhos que lhe chegarem, de quem lhe chegar. Como se encontra numa subcomunidade maligna, onde a sua rede social efetiva mudou drasticamente, os conselhos que recebe provêm de indivíduos violentos que esperam que o sujeito também aja violentamente. A "comunidade fantasma" que o sujeito começa a incorporar é mais violenta que a anterior, mas oferece ao sujeito uma resposta aceitável à experiência social traumática que ele sofreu. Agora, apesar de ter adquirido uma nova "comunidade fantasma" que o permite compreender a experiência anterior e de se sentir uno novamente, ainda falta colocar em prática esta "comunidade fantasma" provisória.

A terceira fase, práxis, procura, tal como o nome indica, colocar a "comunidade fantasma" provisória em prática. Mas qualquer experiência social não basta, é preciso que o sujeito se depare com uma experiência social semelhante à que provocou todo o processo inicial de ruptura. Esta nova experiência é que será o teste crucial à consolidação da nova "comunidade fantasma". Se obtiver sucesso o sujeito torna-se confiante na nova "comunidade fantasma", talvez sendo necessário fazer apenas pequenos ajustes, mas se falhar, todo o processo doloroso de reconstrução terá de repetir-se. É necessário, claramente, que o sujeito consiga suportar novamente todo o processo, mas até conseguir ultrapassar o teste crucial da experiência social, o sujeito encontra-se num estado de limbo, o que pode tornar-se particularmente perigoso:

\begin{abstract}
Staying in limbo for a prolonged period may eventually generate enough anxiety in a person to produce an end result similar in nature, if not degree, to permanent disorganization (ATHENS, 1995, p.578).
\end{abstract}

Supondo que o sujeito enfrente o teste crucial da experiência e o consiga ultrapassá-lo com sucesso, tem início a quarta fase. Em consolidação, o sujeito consegue finalmente organizar todos aqueles pensamentos e emoções conflituosos que haviam emergido com a experiência social traumática. No entanto, para tornar a nova "comunidade fantasma" de provisória a permanente, ou seja, para consolidar a nova "comunidade fantasma", o novo sujeito tem de ser reconhecido pelos outros indivíduos da subcomunidade que habita e que fazem agora parte da sua rede social efetiva. Contudo, apesar do reconhecimento pelos outros indivíduos, o sujeito tem, ele próprio, que decidir se aceita continuar com o novo ego que se formou. Caso rejeite-o, o sujeito terá, tal como anteriormente, repetir todo o processo de reconstrução, ou cair num estado de permanente desorganização psicológica (ATHENS, 1995; RHODES, 1999).

Supondo, novamente, que o sujeito aceite o novo ego, começa a quinta e última fase de segregação social (ibid.). Esta fase corresponde ao que Arnett (1995) refere como processo de associação seletiva. O novo sujeito paira agora pela subcomunidade por um grupo que se assemelhe a ele e à sua (agora do sujeito) expectativa do que deve ser a norma de conduta, de acordo com a sua nova "comunidade fantasma", de outros indivíduos. Tal como refere Arnett:

Whithin a given peer or friendship group, peers generally expect conformity. This is as likely to be true in adulthood as in childhood; adults, like children, tend to choose as friends people who are similar to themselves in various ways (Arnett, 1995, p. 620).

No entanto, este processo de associação seletiva funciona para ambos os lados: o novo sujeito procura outros que se assemelhem a ele, mas a sua transformação drástica pode também ser consequência da exigência de conformidade do novo grupo de indivíduos a que o sujeito se viu forçado a se juntar por ter que modificar a sua anterior rede social à nova subcomunidade para a qual se mudou.

No final de todo este processo, temos um sujeito que começou como uma pessoa não violenta, mas que através de uma transformação dramática (que tanto poderá ter sido imposta por um novo grupo a que se associou como pela ocorrência de uma experiência social traumática), terminou por adquirir uma "comunidade fantasma" violenta, tornando-se ele próprio uma pessoa violenta, adaptada à nova subcomunidade que habita, e capaz de lidar com 
experiências sociais que desconhecia anteriormente. Como parte de um grupo, o sujeito vai participar da socialização dos outros membros e, inclusive, possivelmente provocar uma experiência social traumática a outro indivíduo e/ou ingressar na "comunidade fantasma" de outro indivíduo. Na perspectiva da comunidade maior, este sujeito passou de um indivíduo pacífico a um indivíduo que pratica atos desviantes como manifestação cultural da sua integração em uma subcomunidade maligna.

Portanto, existem diferentes subcomunidades, com diferentes formas de estabelecer dominância, povoadas por diferentes tipos de indivíduos e com uma forma de tanto "replicar" os tipos de indivíduos, como de manter a sua subcultura.

De que forma pode a análise de redes sociais prevenir a replicação do comportamento desviante?

De acordo com o modelo proposto, o problema centra-se nas normas estabelecidas para resolver disputas de dominância e no processo de transformação dramática que, como processo de socialização, tem a capacidade de "formatar" um sujeito ao contexto cultural no qual ele se situa. O comportamento desviante é incutido no sujeito através da sua socialização numa subcomunidade, com a sua própria subcultura que admite ao seu nível vários tipos de comportamentos não aceitáveis na comunidade maior e na sua cultura.

Tal como refere Sílvia Portugal:

O ponto de partida da investigação não deve ser, portanto, um conjunto de unidades independentes, mas, pelo contrário o conjunto de relações que as interliga. Não se pode querer compreender a estrutura e ignorar as relações que se estabelecem entre os seus elementos (PORTUGAL, 2007, p.7).

O ponto de partida parece ser, então, identificar quais "nós" ou "zonas" em uma rede social de um determinado sujeito/âncora são responsáveis pela transmissão de conteúdo normativo desviante, e forçar alternativas de "nós" socialmente saudáveis (assumindo por saudável o que concorda com as expectativas da comunidade maior).

Se é através da transformação dramática que cada sujeito adquire novos modos de atuar, identificar e influenciar os laços sociais que o sujeito vai utilizar na segunda fase (unidade provisória) durante a procura de conselhos, perspectivas de compreender o mundo é uma medida fulcral para incutir no sujeito membros na sua "comunidade fantasma" provisória que suportem e dirijam o sujeito a atos socialmente saudáveis.

No entanto, Marsden e Lin indicam ainda uma característica que a análise de redes permite, e que é deveras importante no modelo aqui proposto:

[Análise de redes] oferece novas abordagens para a descrição e estudo da estrutura social e para lidar com o problema complexo de integrar diferentes níveis de análise: o modo como a ação individual cria a estrutura social; o modo como a estrutura social, uma vez criada, constrange a ação individual e coletiva; o modo como as atitudes e comportamentos dos atores são determinados pelo contexto social em que a ação decorre (MARSDEN; LIN, 1985, citado por PORTUGAL, 2007, p.30) (ênfase adicionada).

\section{Conclusão}

O sistema exposto nestas páginas tenta demonstrar como o grau de variação permitida no processo de socialização de uma determinada subcomunidade e subcultura aflui diretamente no grau de individualismo presente nessa mesma subcomunidade. A internalização das atitudes e expectativas dessa subcomunidade perpetuam o tipo de indivíduo que mantém a subcomunidade no seu tipo atual, permitindo que este integre ativamente o processo de socialização dos novos membros. Tal como referido no início, um ciclo vicioso de socialização-incorporação-socialização. Se as atitudes e expectativas da subcomunidade são dissonantes com a comunidade maior, é fomentado o comportamento desviante nos membros dessa subcomunidade.

Através da análise de redes, pelo que nos informam Marsden e Lin, será possível "integrar diferentes níveis de análise" (MARSDEN; LIN, 1985, citado por PORTUGAL, 2007), ou seja, procurar especificamente o modo como a estrutura social influencia o comportamento individual e coletivo, e como o comportamento individual e coletivo 
influencia a estrutura social. Só após uma análise da rede social de uma subcomunidade a diferentes níveis de abstração se poderá inferir sobre a melhor forma de manipular os laços sociais de modo a provocar uma transformação dramática socialmente saudável não só nos membros da subcomunidade, mas também na subcomunidade em si.

\section{Referências}

ADLER, F.; MUELLER, G.; LAUFER, W. S. Criminology sixth edition. New York: McGraw-Hill, 2007.

ARNETT, J. J. Broad and narrow socialization: the family on the context of a cultural theory. Journal of Marriage and the Family, v.57, p.617-628, 1995.

ATHENS, L. H. The creation of dangerous violent criminals. Chicago: University of Illinois Press, 1992.

. The self as soliloquy. The sociological Quarterly, v.35, n.3, p.521-532, 1994.

Dramatic self-change. The Sociological Quarterly, v.36, n.3, p.571-586, 1995.

Violent criminal acts and actors revisited. Chicago: University of Illinois Press, 1997.

Dominance, ghettos and violent crime. The $\overline{\text { Sociological Quarterly, v.39, n.4, p.673-691, } 1998 .}$
Violent encounters: violent engagements, skirmishes, and tiffs. Journal of Contemporary Ethnography, p.34: n.6, p.1-48, 2005.

Radical interactionism: going beyond Mead. Journal for the Theory of Social Behaviour, v.37, n.2, p.137-165, 2007.

BARNES, G. M.; HOFFMAN, J. H.; WELTE, J. W.; FARRELL, M. P.; DINTCHEFF, B. A. Adolescent's time use: effects on substance use, delinquency and sexual activity. Journal of Youth and Adolescence, v.36, p.697710, 2007

MEAD, G. H. The genesis of the self and social control. International Journal of Ethics, v.35, n.3, p.251-277, 1925.

MITCHELL, J. C. Social networks. Annual Review of Anthropology, v.3, p.279-299, 1974.

PAYNE, A. A.; SALOTTI, S. A comparative analysis of social learning and social control theories in the prediction of college crime. Deviant behavior, v.28, e.6, p.553-573, 2007.

PORTUGAL, S. Contributos para uma discussão do conceito de rede na teoria sociológica. Coimbra: Oficina do CES n. ${ }^{\circ}$ 271, mar. 2007.

RHODES, R. Why they kill: the discoveries of a maverick criminologist. New York: Alfred A. Knopf, 1999.

Recebido em janeiro de 2014. Aceito em fevereiro de 2014. 